\title{
Quantitative genetics of juvenile hormone esterase, juvenile hormone binding and general esterase activity in the cricket Gryllus assimilis
}

\author{
XUN GU† \& ANTHONY J. ZERA* \\ School of Biological Sciences, University of Nebraska, Lincoln, Nebraska 68588, U.S.A.
}

\begin{abstract}
Heritabilities and genetic, environmental and phenotypic correlations were estimated for two endocrine traits (juvenile hormone esterase (JHE) and juvenile hormone binding (JHB) activity) and one non-endocrine trait (general esterase activity (GE)) in the cricket Gryllus assimilis. Genetic parameters were estimated in three stages of the last stadium as well as in the entire last stadium. Significant additive genetic heritabilities were observed for each trait for activities pooled over all developmental stages. For JHE and JHB, significant heritabilities were also observed within most developmental stages. This indicates that these endocrine features have sufficient genetic variability during most periods of the last stadium to respond rapidly to selection. Significant phenotypic correlations were observed in eight of nine pairwise comparisons between the three traits in the three stages. Significant additive genetic correlations were observed between JHE and JHB and between JHE and GE for activities pooled over all developmental stages. Nearly all phenotypic and additive genetic correlations between the same trait in different developmental stages were significant. This indicates that these three traits are highly intercorrelated and should evolve in concert. Of particular note is the positive phenotypic and genetic correlation between JHE and JHB which suggests that these two traits may be coordinately regulated and may function in concert to reduce the $\mathrm{JH}$ titre. This is, to our knowledge, the first quantitative-genetic analysis of hormonal features of an insect.
\end{abstract}

Keywords: genetic correlation, Gryllus, heritability, juvenile hormone, juvenile hormone binding, juvenile hormone esterase.

\section{Introduction}

Genetic analyses of naturally occurring physiological variation are relatively uncommon. This is so despite an increasing appreciation of the utility of genetic information for understanding the evolution of physiological traits (Arnold, 1987; Feder, et al., 1987; Bennett \& Huey, 1990; Huey et al., 1991; Garland \& Carter, 1994). The lack of genetic information on physiological diversity is nowhere more apparent than for insect endocrine characters. Only rudimentary information is available on any aspect of the population genetics of endocrine variation (Zera \& Tiebel, 1989; Zera \& Holtmeier, 1992, and references therein), despite a wealth of data on other aspects of insect endocrinology (Downer \& Laufer,

*Correspondence.

†Present address: Human Genetics Center, University of Texas Health Science Center at Houston, TX 77225, U.S.A.
1983; Kerkut \& Gilbert, 1985). There are currently no reports on even the most basic quantitativegenetic parameters, heritability and genetic correlation, for any insect endocrine feature.

The present study is the first in a series of quantitative-genetic analyses of endocrine characters in the cricket Gryllus assimilis. The main focus is juvenile hormone esterase (JHE) activity. JHE hydrolyzes juvenile hormone, a key morphogenetic and gonadotrophic hormone (Hammock, 1985; Roe \& Venkatesh, 1990). JHE plays a key role in reducing the JH titre during the last stadium when the concentration of this hormone must be lowered in order for metamorphosis to proceed. The physiological role of JHE has been intensively studied in the closely related cricket, Gryllus rubens (Zera \& Tiebel, 1989; Zera \& Holtmeier, 1992; Zera et al., 1993, and references therein). Preliminary developmental profiles and biochemical characterization of JHE have recently 
been reported in $G$. rubens and $G$. assimilis (Zera et al., 1992; Gu \& Zera, 1994, and references therein).

The present study also investigated the quantitative genetics of juvenile hormone binding (JHB) and general esterase (GE) activity. $\mathrm{JH}$ binding activity results from a protein which transports $\mathrm{JH}$ in the haemolymph and protects it from nonspecific degradation and nonspecific binding (Goodman, 1990; Trowell, 1992). General esterase (GE) activity results from a group of enzymes whose functions are poorly understood and which do not appear to be important in JH titre regulation. Preliminary developmental profiles of $\mathrm{JHB}$ and $\mathrm{GE}$ as well as biochemical characterizations of GE in $G$. assimilis have previously been reported (Gu \& Zera, 1994).

The purpose of the present study was to estimate: (i) heritabilities for JHE, JHB and GE activities during various periods of juvenile development; and (ii) phenotypic, genetic and environmental correlations between these traits. In a companion study, direct and correlated responses to selection on JHE activity were measured (Zera \& Zhang, 1995).

\section{Materials and methods}

\section{General}

Gryllus assimilis is widely distributed throughout the West Indies and in South and Central American countries bordering on the Caribbean (Alexander \& Walker, 1962). It has recently been introduced into Florida. The population used in the present study was derived from 15 females taken from a laboratory stock of Dr T. J. Walker, Department of Entomology and Nematology, University of Florida. Walker's stock, in turn, was derived from individuals collected from a field near Homestead, Florida. Crickets had been reared for several years in Walker's colony and for several years in Nebraska prior to the present study. In Nebraska, crickets were raised at $28^{\circ} \mathrm{C}$ under a $16 \mathrm{~h}$ light: $8 \mathrm{~h}$ dark photoregime and were fed the dry diet described in Zera \& Rankin (1989).

\section{Breeding design and sampling}

A standard half-sib breeding design was used to estimate the various quantitative-genetic parameters (Becker, 1984; Falconer, 1989). Eighteen randomly chosen males were each mated to four randomly chosen females. In five matings no progeny were produced and thus 67 half-sib families were obtained. Progeny from individual families were raised through the penultimate stadium in $30 \times 15 \times 8 \mathrm{~cm}$ plastic boxes containing cricket food, a water bottle and a moist piece of cotton to increase humidity. During the penultimate stadium, crickets were checked daily and those having moulted into the last stadium during the past $24 \mathrm{~h}$ were placed singly in a $500 \mathrm{~mL}$ plastic cup with food and water. Newly moulted crickets were designated as day-0 individuals. Haemolymph samples were taken from crickets of each age from day 2 to day 10 of the last-stadium. Each cricket was bled only once and each haemolymph sample was derived from a single cricket. The ages of the last stadium were chosen to span the range of ages of the 10-day last stadium (Gu \& Zera, 1994).

\section{Enzyme activity and binding assays}

Assays of haemolymph juvenile hormone esterase (JHE), juvenile hormone binding (JHB) and general esterase activities were measured as described in $\mathrm{Gu}$ \& Zera (1994).

\section{Statistical analyses}

Because sample sizes were modest $(60-80)$ for individual days of the last stadium, heritabilities and correlations were estimated on JHE, GE and JHB activities grouped into early (days 2-3), middle (days 4-6) and late stages (days 7-10). These groups correspond to prepeak, peak and postpeak portions of the JHE and GE activity profiles, respectively (Fig. 1). Prior to statistical analyses, residual, log-transformed enzyme activities $\left(Y_{i j}\right)$ were computed for JHE and $\mathrm{GE}$ as follows: $Y_{i j}=[\log$ $\left.X_{i j}-\log \left(\bar{X}_{i}\right)\right]$ where $X_{i j}$ is the enzyme activity in the $\mathrm{jth}$ individual of the $i$ th age and where $\bar{X}_{i}$ is the mean activity of all individuals of the $i$ th age. Residuals were computed in a similar manner for JHB activities but they were not log-transformed (i.e. $\left.Y_{i j}=X_{i j}-\bar{X}_{i}\right)$. Residuals were computed to remove the considerable (up to three-fold) effect of variation in developmental stage (age) on enzyme/binding activities (Fig. 1). JHE and GE residuals were log-transformed to eliminate the correlation between their means and variances. Sample distributions were also tested and shown not to depart from normality prior to statistical analyses.

Heritabilities were estimated using a standard nested ANOVA while correlations were estimated by nested ANCOVA (Becker, 1984). Data were analysed by the computer program sPSs (SPSs/PC ${ }^{+}$, Advanced Statistic $^{\mathrm{TM}}$ v.2.0, 1988; SPSS). Narrow-sense heritabilities $\left(h_{\mathrm{A}}^{2}\right)$ were calculated in the standard fashion as $4 V_{\mathrm{S}} / V_{\mathrm{P}}$ where $V_{\mathrm{S}}$ is the between-sire variance 

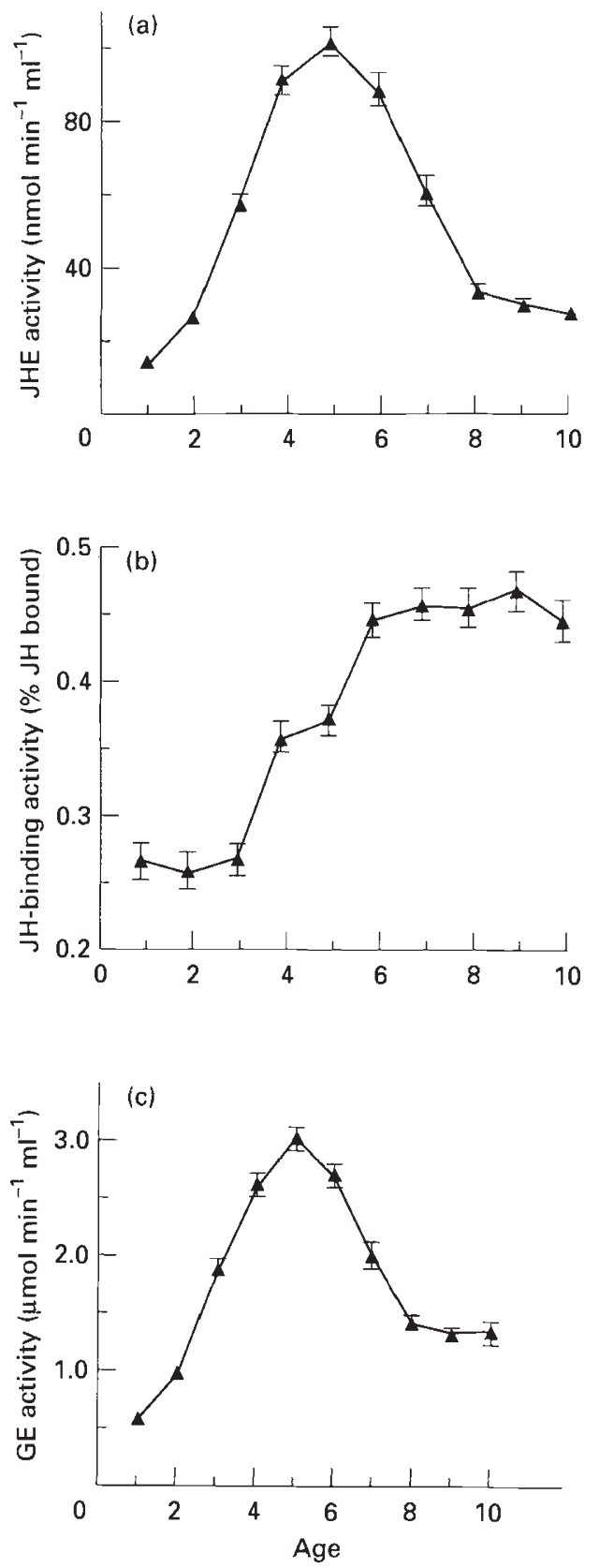

Fig. 1 Haemolymph juvenile hormone esterase (a), juvenile hormone binding (b) and general esterase activities (c) in last-stadium Gryllus assimilis as a function of age. Sample sizes for each age ranged from 52 to 83 (median $=64$ ). Bars are standard errors which in some cases are smaller than the symbol. Age refers to the number of days after the moult to the last stadium. See Materials and methods and Gu \& Zera (1994) for experimental details.

component and $V_{\mathrm{P}}$ is the total phenotypic variance obtained in the nested ANOVA. Non-additive heritability $\left(h_{\mathrm{D}}^{2}\right)$ was calculated as $4\left(V_{\mathrm{D}}-V_{\mathrm{S}}\right) / V_{\mathrm{P}}$ where $V_{\mathrm{D}}$ is the between-dam variance component. $h_{\mathrm{D}}^{2}$ repre- sents the proportion of the phenotypic variance attributable to dominance variance plus variance components resulting from maternal effects as well as common environment. In many cases, the dominance variance $\left(V_{\mathrm{D}}\right)$ was found to be negative (see Results). When this occurred $V_{\mathrm{D}}$ was set equal to zero before computing the remaining variance components (see Clark, 1990). Approximate standard errors for the heritability estimates were computed using formulae in Becker (1984). F-tests of the among-sire variance vs. the error variance were used to determine the significance of the heritabilities. Additive genetic, environmental and phenotypic correlations and their standard errors were computed in an analogous manner via nested ANCOVAS using the formulae in Becker (1984). Between-stage correlations (e.g. JHE activity during the early vs. middle stage) cannot be directly estimated by this method because each cricket was measured during a single developmental stage. These correlations were estimated using mean progeny values obtained during different stages for individual sires (Via, 1984). The statistical significance of all correlations was determined by two-tailed $t$-tests.

\section{Results}

\section{$J H E, G E$ and $J H B$ activities}

Approximately 620 last-stadium G. assimilis were scored for juvenile hormone esterase (JHE), general esterase (GE) and juvenile hormone binding (JHB) activities (Fig. 1). Developmental variation of JHE activity during the last stadium consisted of a single midstadium peak on day 5 that was about 10 -fold higher than activities at the beginning of the stadium. A very similar developmental profile was observed for GE activity in last-stadium $G$. assimilis. In contrast, juvenile hormone binding (JHB) activity rose continuously from its lowest level at the beginning of the stadium to a plateau which began on day 6 and remained until the end of the stadium. Developmental profiles for JHE, GE and JHB during the last stadium were similar for males and females and were essentially identical to those obtained in a preliminary study (Gu \& Zera, 1994).

\section{Heritabilities and genetic variances}

Significant narrow-sense heritabilities $\left(h_{\mathrm{A}}^{2}\right)$ were obtained for JHE, JHB and GE activities pooled over all developmental stages of the last stadium (Table 1). Significant heritabilities were also 
obtained for JHE and JHB activities within most (five of six) individual developmental stages. In contrast, GE heritabilities were only significant in the middle stage. These data document a significant additive genetic component to the phenotypic variance for JHE and JHB throughout most of the last stadium. No significant ontogenetic variation was observed for the heritabilities of any trait (ANOVA). However, additive genetic variances $\left(V_{\mathrm{A}}\right)$ differed significantly among the three stages of the last stadium for JHE $(P<0.005)$ and JHB $(P<0.005)$ but not for GE $(P>0.05$; Bartlett's test of the homogeneity of variances). The heterogeneity resulted mainly from the decrease in $V_{\mathrm{A}}$ for $\mathrm{JHE}$ and the increase in $V_{\mathrm{A}}$ for JHB during the late stage of the last stadium (Table 1). In contrast, phenotypic variances $\left(V_{\mathrm{P}}\right)$ were statistically homogeneous among the three stages of the last stadium for JHE, JHB and GE (Bartlett's test; Table 1). Essentially identical patterns of developmental variation and results of statistical analyses were obtained for heritabilities and variances when ages were grouped slightly differently $($ early $=$ days $2-3$; middle stage $=$ days $4-7$; late stage $=$ days $8-10$; data not shown).

In contrast to the significant additive heritabilities, non-additive heritabilities $\left(h_{\mathrm{D}}^{2}\right)$ did not differ from zero in any case (Table 1). These data indicate that dominance and maternal effects make no measurable contribution to the phenotypic variance in JHE, $\mathrm{GE}$ and $\mathrm{JHB}$ activities. In many cases, $V_{\mathrm{D}}$ was negative leading to a biologically meaningless negative $h_{\mathrm{D}}^{2}$. A similar situation was encountered by Clark (1990). He noted that previous simulations by Bridges \& Knapp (1987) indicate that $V_{\mathrm{D}}$ is the variance component most likely to be negative because of sampling error. Negative $V_{\mathrm{D}}$ can also arise from a variety of other causes such as epistasis and nonrandom mating.

\section{Correlations}

Positive phenotypic correlations that were significantly greater than zero were observed between each pair of endocrine traits in each stage, except for $\mathrm{GE}$ and JHB during the early last stadium (Table 2). Significant additive genetic correlations were observed between JHE and GE and between JHE and JHB for activities pooled over all developmental stages and for activities within one or two of the developmental stages. In contrast, additive

Table 1 Additive genetic $\left(h_{\mathrm{A}}^{2}\right)$ and dominance $\left(h_{\mathrm{D}}^{2}\right)$ heritabilities and additive genetic $\left(V_{\mathrm{A}}\right)$ and phenotypic $\left(V_{\mathrm{P}}\right)$ variances for juvenile hormone esterase (JHE), juvenile hormone binding (JHB) and general esterase (GE) activities during various stages of the last stadium of Gryllus assimilis

\begin{tabular}{|c|c|c|c|c|c|c|}
\hline \multicolumn{2}{|c|}{$\begin{array}{l}\text { Character/ } \\
\text { stage } \dagger\end{array}$} & \multirow{2}{*}{$\begin{array}{c}\begin{array}{c}\text { Sample } \\
\text { size } \ddagger\end{array} \\
144\end{array}$} & \multirow{2}{*}{$\frac{\mathrm{h}_{\AA}^{2} \pm \mathrm{SE}}{0.57 \pm 0.27^{* *} \S}$} & \multirow{2}{*}{$\frac{\mathrm{h}_{\mathrm{D}}^{2} \pm \mathrm{SE}}{0.0+\uparrow}$} & \multirow{2}{*}{$\frac{\mathrm{V}_{\mathrm{A}}}{0.10}$} & \multirow{2}{*}{$\frac{\mathrm{V}_{\mathrm{P}}}{0.18}$} \\
\hline JHE & Early & & & & & \\
\hline & Middle & 223 & $0.55 \pm 0.25^{* *}$ & 0.0 & 0.12 & 0.22 \\
\hline & Late & 260 & $0.23 \pm 0.22$ & $0.37 \pm 0.34$ & 0.04 & 0.20 \\
\hline & Combined & 627 & $0.34 \pm 0.13^{* *}$ & $0 . \overline{0}$ & 0.07 & 0.20 \\
\hline \multirow[t]{4}{*}{ GE } & Early & 144 & $0.39 \pm 0.19$ & 0.0 & 0.05 & 0.15 \\
\hline & Middle & 223 & $0.38 \pm 0.23^{*}$ & $0.017 \pm 0.20$ & 0.05 & 0.14 \\
\hline & Late & 260 & $0.26 \pm 0.22$ & 0.0 & 0.04 & 0.16 \\
\hline & Combined & 627 & $0.25 \pm 0.11 *$ & 0.0 & 0.04 & 0.14 \\
\hline \multirow[t]{4}{*}{ JBH } & Early & 144 & $0.67 \pm 0.33^{*}$ & 0.0 & 0.79 & 1.17 \\
\hline & Middle & 223 & $0.51 \pm 0.28^{*}$ & 0.0 & 0.63 & 1.22 \\
\hline & Late & 260 & $0.79 \pm 0.35^{*}$ & 0.0 & 1.05 & 1.33 \\
\hline & Combined & 627 & $0.36 \pm 0.17^{*}$ & 0.0 & 0.42 & 1.20 \\
\hline
\end{tabular}

†Stage $=$ early (days 2-3), middle (days 4-6) and late (7-10) portions of the last stadium; see Materials and methods for details on grouping.

\$Sample size is the number of individual crickets analysed.

§Significance of the heritability was determined by an $F$-test of the among-sire variance vs. the error variance $\left({ }^{*} P<0.05,{ }^{* *} P<0.025\right)$. Values without an asterisk were not significantly different from zero.

$\dagger \uparrow$ Zero value without a standard error denotes a negative value for $h_{\triangleright}^{2}$ (see Materials and methods). 
genetic correlations between GE and JHB were not significant either for activities pooled over all developmental stages or for activities within any individual stage. As was the case with the heritabilities, no ontogenetic variation in additive-genetic, environmental or phenotypic correlations was seen. Significant environmental correlations were observed only between JHE and GE and were seen during each stage (Table 2). Finally, strong and highly significant additive genetic and phenotypic correlations were typically observed (15 of 18 cases) for comparisons of the same endocrine trait between different developmental stages (Table 3).

\section{Discussion}

Two important results were obtained in the present study. The first is the documentation of significant narrow-sense heritabilities $\left(h_{\mathrm{A}}^{2}\right)$ for JHE, JHB and GE activities during the entire last stadium and for

Table 2 Additive genetic $\left(r_{\mathrm{A}}\right)$, environmental $\left(r_{\mathrm{E}}\right)$, phenotypic $\left(r_{\mathrm{P}}\right)$ correlations and their standard errors (SE) for pairwise comparisons of juvenile hormone esterase (JHE), juvenile hormone binding (JHB) and general esterase (GE) activity during various stages of the last stadium of Gryllus assimilis

\begin{tabular}{lcccc}
\hline $\begin{array}{l}\text { Character/ } \\
\text { stage }\end{array}$ & $\begin{array}{c}\text { Sample } \\
\text { size }\end{array}$ & $r_{\mathrm{A}} \pm \mathrm{SE}$ & $r_{\mathrm{E}} \pm \mathrm{SE}$ & $r_{\mathrm{P}} \pm \mathrm{SE}$ \\
\hline JHE vs. GE & & & & \\
$\quad$ Early & 144 & $0.61 \pm 0.24^{* *}$ & $0.83 \pm 0.28^{* *}$ & $0.67 \pm 0.08^{* * *}$ \\
Middle & 223 & $0.70 \pm 0.19^{* * *}$ & $0.75 \pm 0.19^{* * *}$ & $0.69 \pm 0.05^{* * *}$ \\
Late & 260 & $0.73 \pm 0.60$ & $0.62 \pm 0.16^{* * *}$ & $0.65 \pm 0.16^{* * *}$ \\
Combined & 627 & $0.71 \pm 0.14^{* * *}$ & $0.65 \pm 0.06^{* * *}$ & $0.66 \pm 0.04^{* * *}$ \\
JHE vs. JHB & & & & \\
Early & 144 & $0.39 \pm 0.32$ & $0.32 \pm 0.58$ & $0.31 \pm 0.10^{* *}$ \\
Middle & 223 & $0.64 \pm 0.19^{* * *}$ & $0.11 \pm 0.29$ & $0.36 \pm 0.05^{* * *}$ \\
Late & 260 & $0.55 \pm 0.38$ & $0.32 \pm 0.44$ & $0.32 \pm 0.10^{* * *}$ \\
Combined & 627 & $0.63 \pm 0.18^{* * *}$ & $0.17 \pm 0.10$ & \\
GE vs. JHB & & & & $-0.05^{* * *}$ \\
$\quad$ Early & 144 & $-0.26 \pm 0.27$ & $0.44 \pm 0.35$ & $0.13 \pm 0.06^{*}$ \\
Middle & 223 & $0.10 \pm 0.32$ & $0.24 \pm 0.24$ & $0.20 \pm 0.09^{*}$ \\
Late & 260 & $0.42 \pm 0.35$ & $0.10 \pm 0.50$ & $0.12 \pm 0.05^{*}$ \\
Combined & 627 & $0.22 \pm 0.31$ & $0.07 \pm 0.13$ & \\
\hline
\end{tabular}

Stages and significance levels (denoted by asterisks) are the same as those in Table $1\left({ }^{* * *} P<0.005\right)$. Significance of correlations was determined by two-tailed $t$-tests with $\mathrm{H}_{\mathrm{o}}: r=0$.

Unless otherwise noted, correlations are positive.

Table 3 Additive genetic (phenotypic) autocorrelations between different developmental stages of the last stadium of Gryllus assimilis for juvenile hormone esterase (JHE), general esterase (GE) or juvenile hormone binding (JHB) activity

\begin{tabular}{lccc}
\hline & \multicolumn{3}{c}{ Stage } \\
\cline { 2 - 4 } Trait & Early vs. middle $\dagger$ & Middle vs. late & Early vs. late \\
\hline JHE & $0.75 \pm 0.20^{* *}$ & $0.87 \pm 0.15^{* * *}$ & $0.41 \pm 0.56$ \\
& $(0.33 \pm 0.04)^{* * *}$ & $(0.39 \pm 0.05)^{* * *}$ & $(0.39 \pm 0.05)^{* * *}$ \\
GE & $0.68 \pm 0.29^{*}$ & $0.75 \pm 0.32^{*}$ & $0.59 \pm 0.42$ \\
& $(0.39 \pm 0.05)^{* * *}$ & $(0.34 \pm 0.04)^{* * *}$ & $(0.15 \pm 0.08)$ \\
JHB & $0.75 \pm 0.29^{* *}$ & $0.88 \pm 0.11^{* * *}$ & $0.84 \pm 0.14^{* * *}$ \\
& $(0.32 \pm 0.04)^{* * *}$ & $(0.39 \pm 0.06)^{* * *}$ & $(0.28 \pm 0.10)^{* *}$ \\
\hline
\end{tabular}

$\dagger$ See Table 1 or Materials and methods for specific days of each stage.

Asterisks denote values that were significantly different from zero $\left({ }^{*} P<0.05\right.$,

${ }^{*} P<0.025$ and ${ }^{* * *} P<0.005$, respectively; two-tailed $t$-tests). 
JHE and JHB during most (five of six) of the individual stages of last-stadium $G$. assimilis. These data document the existence of genetic variation for JHE and JHB throughout the last stadium of $G$. assimilis. It is unclear whether this is typical of other insect endocrine traits, as no heritability estimates for these traits are available. The activity of GE, an enzyme without any demonstrated endocrine function, only exhibited a significant heritability during the middle of the last stadium. At the very least, this suggests that heritabilities for insect endocrine traits are not lower than those for enzymes involved in intermediary metabolism. The similarity between the JHE and JHB heritabilities and those for enzymes of intermediary metabolism in Drosophila (Clark, 1990) is consistent with this idea. The nonsignificant dominance variance for JHE, GE and JHB in G. assimilis (Table 1) is also similar to that observed for enzymes of intermediary metabolism in Drosophila (Clark, 1990).

As JHE, JHB and GE have significant narrowsense heritabilities, each of these traits should respond to artificial selection applied during the early-mid last stadium. This has recently been experimentally verified in an independently derived population of $G$. assimilis. Selection on haemolymph JHE activity on the third day of the last stadium resulted in a rapid response to selection (realized $h^{2}=0.26 \pm 0.04 ;$ Zera \& Zhang, 1995). In that JHE selection experiment, JHB and GE activities also exhibited significant indirect responses to selection (A. J. Zera \& R. Schwartz, unpublished data). Thus, results of the present half-sib analysis and a subsequent selection experiment (Zera \& Zhang, 1995) are consistent in showing that insect endocrine features have the capacity to evolve rapidly, at least in short-term laboratory studies. An important but as yet unstudied issue concerns the degree to which these heritabilities and responses to selection measured in the laboratory also occur in the field where environmental variance is undoubtedly higher (Prout \& Barker, 1989; Riska et al., 1989).

\section{Quantitative genetics: correlations}

The second important finding of the present study is the significant phenotypic and genetic correlations between some traits in G. assimilis (Tables 2 and 3). As is the case for the narrow-sense heritabilities, this is the first documentation of significant correlations between endocrine traits in an insect. From an evolutionary perspective, genetic correlations are of special interest as they determine the extent to which traits are constrained to evolve in concert
(Lande, 1979; Arnold, 1987; Price \& Langen, 1992). Results of the present study indicate that short-term selection on JHE should result in correlated responses to selection on JHB and GE. As mentioned above, this has recently been experimentally verified in a subsequent selection experiment (A. J. Zera \& R. Schwartz, unpublished data).

The strong between-stage correlations for JHE, $\mathrm{JHB}$ and GE are particularly intriguing and indicate that the developmental profiles for each of these three traits should evolve as a correlated unit. This has also been verified experimentally. When JHE activity was selected for increased or decreased activity on the third day of the last stadium, the indirect response in enzyme activities on days 1,5 and 8 was equivalent to the direct response. That is, the magnitude of the entire profile was elevated or lowered while the shape of the profile was not altered (Zera \& Zhang, 1995).

From a functional perspective, the positive genetic correlation between JHE and JHB is unexpected and provides a potentially new insight into the functional relationship between these two endocrine features. JHE and JHB are typically thought to have antagonistic functions, with JHE involved in the degradation of $\mathrm{JH}$ whereas $\mathrm{JHB}$ is involved in transportation and protection of $\mathrm{JH}$ from degradation (Hammock, 1985; Goodman, 1990). One might therefore expect these traits to be uncorrelated or negatively correlated. However, JHB could conceivably be involved in the degradation of $\mathrm{JH}$ by removing this hormone from lipid depots where it may be protected from degradation (Tobe \& Stay, 1985) and delivering it to the haemolymph where there is high JHE activity. The positive phenotypic and genetic correlations between JHE and JHB suggests that these two factors may be coordinately regulated and provide support for this idea.

The strong and positive genetic and phenotypic correlations between JHE and GE are also consistent with genetic coregulation of these two enzymes or sets of enzymes. Although there are no data on this topic in $G$. assimilis, there is some experimental evidence suggesting that JHE and GE in the lepidopterans Manduca sexta and Trichoplusia ni are coregulated by a neurohormone (Roe \& Venkatesh, 1990). Importantly, we have previously demonstrated that JHE and GE activities result from different esterase enzymes (Gu \& Zera, 1994). Thus, the correlation between these two activities in $G$. assimilis is not a trivial consequence of two different measures of the same enzyme activity.

In summary, we have documented significant phenotypic, environmental and additive genetic 
correlations and significant additive genetic heritabilities for several endocrine traits in an insect. These data as well as those obtained in a subsequent selection experiment on JHE activity provide the foundation for an analysis of the nature of genetic variation and covariation of insect endocrine traits.

\section{Acknowledgements}

We thank Dr T. J. Walker for supplying us with $G$. assimilis and two anonymous reviewers for their comments on a previous version of this manuscript. This research was supported by NSF grant IBN-9105257 to A.J.Z.

\section{References}

ALEXANDER, R. D. AND WALKER, T. J. 1962. Two introduced field crickets new to eastern United States (Orthoptera: Gryllidae). Ann. Entomol. Soc. Am., 55, 90-94.

ARNOLD, s. J. 1987. Genetic correlation and the evolution of physiology. In: Feder, M. E., Bennett, A. F. Burggren, W. W. and Huey, R. B. (eds) New Directions in Ecological Physiology, pp. 189-215. Cambridge University Press, Cambridge.

BECKER, w. A. 1984. Manual of Quantitative Genetics, 4th edn, pp. 119-124. Academic Enterprises, Pullman, Washington.

BENNETT, A. F. AND HUEY, R. B. 1990. Studying the evolution of physiological performance. In: Futuyma, D. J. and Antonovics, J. (eds) Oxford Surveys in Evolution, vol. 7, pp. 251-284. Oxford University Press, Oxford.

BRIDGES, W. C. AND KNAPP, S. J. 1987. Probabilities of negative estimates of genetic variances. Theor. Appl. Genet., 74, 269-274.

CLARK, A. G. 1990. Genetic components of variation in energy storage in Drosophila melanogaster. Evolution, 44, 637-650.

DOWNER, R. G. H. AND LAUFER, H. (eds). 1983. Endocrinology of Insects. Alan R. Liss, New York.

FALCONER, D. S. 1989. Introduction to Quantitative Genetics, 3rd edn. Longman Scientific and Technical, New York.

FEDER, M. E., BENNETT, A. F., BURGGERN, W. W. AND HUEY, R. B. (eds). 1987. New Directions in Ecological Physiology. Cambridge University Press, Cambridge.

GARLAND, T. J. AND CARTER, P. A. 1994. Evolutionary physiology. Ann. Rev. Physiol., 56, 579-621.

GOODMAN, w. G. 1990. Biosynthesis, titer regulation, and transport of juvenile hormones. In: Gupta, A. P. (ed.) Morphogenetic Hormones of Arthropods, vol. 1, pp. 84-124. Rutgers University Press, New Brunswick.

GU, X. AND ZERA, A. J. 1994. Developmental profiles and characteristics of hemolymph juvenile hormone esterase, general esterase and juvenile hormone binding in the cricket, Gryllus assimilis. Comp. Biochem. Physiol., 107B, 553-560.

HAMMOCK, B. D. 1985. Regulation of the juvenile hormone titer: Degradation. In: Kerkut, G. A. and Gilbert, L. I. (eds) Comprehensive Insect Physiology, Biochemistry and Pharmacology, vol. 7, pp. 431-472. Pergamon Press, New York.

HUEY, R. B., PARTRIDGE, L. AND FOWLER, K. 1991. Thermal sensitivity of Drosophila melanogaster responds rapidly to laboratory natural selection. Evolution, 45, 751-756.

Kerkut, G. A. AND GILBERT, L. I., (eds). 1985. Comprehensive Insect Biochemistry, Physiology and Pharmacology, vols 7 and 8, Endocrinology. Pergamon Press, New York.

LANDE, R. 1979. Quantitative genetic analysis of multivariate evolution as applied to brain:body size allometry. Evolution, 33, 402-416.

PRICE, T. AND LANGEN, T. 1992. Evolution of correlated characters. Trends Ecol. Evol., 7, 307-210.

PROUT, T. AND BARKER, S. F. 1989. Ecological aspects of the heritability of body size in Drosophila buzzatii. Genetics, 123, 801-813.

RISKA, B., PROUT, T. AND TURELLI, M. 1989. Laboratory estimates of heritabilities and genetic correlations in nature. Genetics, 123, 865-871.

ROE, R. M. AND VENKATESH, K. 1990. Metabolism of juvenile hormones: degradation and titer regulation. In: Gupta, A. P. (ed.) Morphogenetic Hormones of Arthropods, vol. 1, pp. 126-179. Rutgers University Press, New Brunswick.

TOBE, S. S. AND STAY, B. 1985. Structure and regulation of the corpora allata. Adv. Insect Physiol., 18, 305-433.

TROWELl, S. C. 1992. High affinity juvenile hormone carrier proteins in the haemolymph of insects. Comp. Biochem. Physiol., 103B, 795-807.

$V_{I A}$, s. 1984. The quantitative genetics of polyphagy in an insect herbivore. II. Genetic correlations in larval performance within and among host plants. Evolution, 38, 896-905.

ZERA, A. J., BORCHER, C. AND GAINES, S. B. 1993. Juvenile hormone degradation in adult wing morphs of the cricket, Gryllus rubens. J. Insect Physiol., 39, 845-856.

ZERA, A. J., GU, X. AND ZEISSET, M. 1992. Characterization of juvenile hormone esterase from genetically-determined wing morphs of the cricket, Gryllus rubens. Insect Biochem. Mol. Biol., 22, 829-839.

ZERA, A. J. AND HOLTMEIER, C. L. 1992. In vivo and in vitro degradation of juvenile hormone-III in presumptive long-winged and short-winged Gryllus rubens. J. Insect Physiol., 38, 61-74.

ZERA, A. J. AND RANKIN, M. A. 1989. Wing dimorphism in Gryllus rubens: genetic basis of morph determination and fertility differences between morphs. Oecologia, 80, $249-255$.

ZERA, A. J. AND TIEBEL, K. C. 1989. Differences in juvenile hormone esterase activity between presumptive macropterous and brachypterous Gryllus rubens: implications for the hormonal control of wing polymorphism. J. Insect Physiol., 35, 7-17.

ZERA, A. J. AND ZHANG, C. 1995. Evolutionary endocrinology of juvenile hormone esterase in Gryllus assimilis: direct and correlated responses to selection. Genetics, 141, 1125-1134. 